\title{
Change in smoking cessation stage over 1 year in patients with schizophrenia: a follow up study in Japan
}

Yuji Higuchi ${ }^{1}$, Masaki Fujiwara ${ }^{2}$, Naoki Nakaya ${ }^{3}$, Maiko Fujimori ${ }^{4}$, Chinatsu Hayashibara ${ }^{5}$, Ryuhei So ${ }^{6}$, Ikuta Shinkawa ${ }^{6}$, Kojiro Sato ${ }^{6}$, Yuji Yada ${ }^{6}$, Masafumi Kodama ${ }^{6}$, Hiroshi Takenaka ${ }^{6}$, Yoshiki Kishi ${ }^{6}, K$ Kyoko Kakeda ${ }^{7}$, Yosuke Uchitomi ${ }^{8}$, Norihito Yamada ${ }^{9}$ and Masatoshi Inagaki ${ }^{10^{*}}$ (D)

\begin{abstract}
Background: We performed a follow up study about willingness and behaviors to quit smoking among smokers with schizophrenia in Japan.

Methods: Participants were outpatients with schizophrenia aged 20-69 years who had been visiting the hospital for $\geq 1$ year as of April 1, 2016, and had visited the hospital more than once in the previous 6 months. A baseline survey on smoking behaviors including current smoking status and smoking cessation stage, was administered in 420 participants that were randomly extracted from a patient pool $(n=680)$ in 2016 , and a follow-up survey was administered in 2017. We calculated the distribution and change in smoking cessation stage, number of smokers and nonsmokers after 1 year, and quitting rate from a naturalistic 1-year smoking-cessation follow up.

Results: The number of baseline respondents was 350; 113 current smokers and 68 former smokers. Among the 113 current smokers, 104 (92.0\%) were followed for 1 year, 79 (70.0\%) were interested in smoking cessation, and only 7 had received smoking cessation treatments at baseline. Among the tracked 104 participants, only 6 (5.8\%) stopped smoking after 1 year. Among the 25 participants who had intentions to quit smoking within 6 months at baseline, 6 (24.0\%) maintained their intention to quit smoking for 1 year, and 16 (64.0\%) did not maintain their intention to quit smoking.
\end{abstract}

Conclusions: Our findings showed that many smokers with schizophrenia were interested in quitting smoking, but few patients received treatment and actually quit smoking. Timely intervention, including the option to receive smoking cessation treatment, is necessary for those patients with schizophrenia who smoke.

Trial registration: UMIN Clinical Trials Registry (UMIN000023874, registered on August 31, 2016).

Keywords: Cigarettes, Mental health, Schizophrenia, Smoking, Tobacco products

\section{Background}

The debate over the relationship between tobacco and schizophrenia has been ongoing for some decades [1-3]. Current smoking prevalence is particularly high among those with schizophrenia, compared with the general population $[4,5]$. The high prevalence of smoking in people with severe mental illness contributes substantially to their premature death because of ischemic heart

\footnotetext{
* Correspondence: minagaki@med.shimane-u.ac.jp

${ }^{10}$ Department of Psychiatry, Faculty of Medicine, Shimane University, 89-1

Enya-cho, Izumo, Shimane 693-8501, Japan

Full list of author information is available at the end of the article
}

disease, cancer, respiratory illnesses [6] or suicidality [7]. Therefore, we must urgently develop effective interventions to help people with schizophrenia quit smoking [8]. Unfortunately, smoking cessation rates among people with mental illness are significantly lower than among those without mental illness [9], despite the fact that most countries have achieved significant annualized rates of decline in smoking prevalence in their general populations [10]. The unchanged high smoking rate among people with mental illness may be due in part to disparities in support schemes for tobacco-use reduction [11].

(c) The Author(s). 2019 Open Access This article is distributed under the terms of the Creative Commons Attribution 4.0 International License (http://creativecommons.org/licenses/by/4.0/), which permits unrestricted use, distribution, and 
Older theories have considered smoking in patients with schizophrenia to be inevitable, as follows: "Tobacco is self-medication for schizophrenia patients because nicotine relieves their symptoms. Therefore, they would not quit smoking, and smoking cessation may exacerbate their illness." However, more recent evidence has failed to support these claims, and has shown that patients with schizophrenia can quit smoking without threatening their mental health recovery [11-13]. Smoking cessation should be an integral part of serious mental illness treatment [14].

Social and cultural contexts influence smoking behavior [15]. However, it is unclear whether findings from Western countries are applicable to Asian countries, because the latter have relatively higher smoking rates, and the smoking rate for women is much lower than that for men [16]. Therefore, it is necessary to research the associations unique to each country between patients' mental-health backgrounds and smoking behavior to support their smoking cessation. Although we reported previously, using anonymized national data, that serious psychological distress increases smoking behavior [17], studies in patients with schizophrenia are limited. Some previous studies have targeted hospitalized patients, but it is difficult to apply these findings to outpatients, who make up the majority of patients with schizophrenia.

Smoking cessation treatment was approved in Japan by governmental health insurance in 2006; however, basic information regarding smoking behavior in patients with schizophrenia is unknown, including whether they intend to quit smoking and how they quit smoking. Although smoking rates in patients with schizophrenia are expected to be high, we assumed that this rate is not attributable specifically to schizophrenia, but instead, to the lack of support for smoking cessation. In a wellknown report in 1918 about private confinement at home, Kure and Kashida described the disparity in health care that patients with schizophrenia were experiencing at that time in Japan as follows: "Hundreds of thousands of mental patients in our country not only have to suffer the misfortune that brought this illness, but they also have to suffer the misfortune of being born in this country." [18] One-hundred years after this report, the discriminatory environment surrounding patients with schizophrenia in Japan might not have changed. For example, smoking is still allowed in many psychiatric hospitals, although approximately $70 \%$ of the hospitals provide information or instructions about smoking cessation support for patients [19]. Thus, we performed an observational survey named as the Study of Health Behavior in People with Schizophrenia (SHEAPS), to gain information on unavoidable disadvantages related to health behavior experienced by these patients, regardless of the nature of the disease.
The purpose of the present survey was to improve the quality of smoking cessation support for smokers with schizophrenia in Japan. Thus, we performed a naturalistic 1-year follow up study about schizophrenia outpatients' smoking behavior and change in smoking behavior according to sex (how many of each sex smoke) and to what extent they are willing to quit smoking, whether or not they had tried to quit smoking, and how they quit.

\section{Methods \\ Study design, ethical approval, and setting}

The SHEAPS has two investigation aims, as follows: (I) cancer-screening behaviors [20]; and (II) smoking behaviors in patients with schizophrenia (the present study).

SHEAPS was registered in a clinical trial registry (UMIN000023874), and was approved by the institutional ethics committee of the Okayama University Graduate School of Medicine, Dentistry, and Pharmaceutical Sciences and Okayama University Hospital (approval number KEN1608-010), and by the institutional review board of Okayama Psychiatric Medical Center (approval number 27-38). Potential participants in SHEAPS were informed that they could decline to participate or withdraw from the study at any time, and all participants provided written informed consent. Participants were recruited in a psychiatric outpatient clinic at the Okayama Psychiatric Medical Center in Japan. This hospital, which has 252 beds and approximately 250 outpatient visits per day, is the core public psychiatric hospital in the area and cares for a wide range of patients, from chronic outpatients to acute and severe inpatients. SHEAPS-(II) was performed from 2016 to 2017, and, to the best of our knowledge, is the first follow-up report investigating schizophrenia outpatients' smoking behavior in Asia.

\section{Participants}

As described previously [20], the SHEAPS inclusion criteria were as follows: On 1 April 2016, patients: (i) were aged 20-69 years; (ii) had visited the hospital for $\geq 1$ year and visited two or more times in the previous 6 months; and (iii) in July 2016 (eligibility assessment time), had been diagnosed with schizophrenia or a schizoaffective disorder (but not other schizophrenia spectrum disorders) according to the fifth edition of the Diagnostic and Statistical Manual of Mental Disorders, by their primary psychiatrist [21]. The exclusion criteria were as follows: (i) patients comorbid for intellectual disabilities and unable to complete the questionnaires; (ii) those with psychiatric or physical symptoms too severe to make study participation appropriate (as judged by their primary psychiatrist); and (iii) those illiterate in Japanese. In accordance with the criteria, 680 patients were pooled 
as eligible participants from the hospital records and judgments by their primary psychiatrist. We estimated that the number of patients we could contact within 3 months would be 420 , based on time- and human resources. These 420 patients were randomly sampled from the patient pool $(n=680)$ in August 2016 using computer-generated random numbers by a researcher blinded to the other information except for the study identification number. We asked the extracted patients to participate in SHEAPS from September to November 2016. The authors contacted most participants directly at the hospital, and also attempted to increase participation by approaching other potential participants via telephone and mail. We tracked participants defined as smokers in our 2016 baseline survey, and asked them to participate again in the follow-up survey from September to November 2017. We did not follow potential smokers who did not smoke at baseline; therefore, we missed some who might have started smoking between the surveys.

\section{Data source and measurements}

Sex and age data were obtained from participants' medical records. Educational level and marital status were self-reported on a paper-based questionnaire. The researchers and a trained research assistant helped participants complete the questionnaires, as needed. In both the 2016 and 2017 surveys, participants were asked to answer questions about smoking status, smoking cessation stage, and the methods of smoking cessation.

\section{Smoking status}

Participants were asked to disclose their smoking status to identify "current smoker". According to World Health Organization guidelines [22], a participant is defined as "a current smoker" if he/she responds "yes" to all the three questions, as follows: "Do you currently smoke?", "Have you smoked at least 100 cigarettes in your entire life or smoked for over 6 months so far?", and "Have you smoked during the 30 days preceding the survey?"

\section{Smoking cessation stage}

For smoking cessation status, participants were asked to select from the following four categories: stage 1 (the immotive stage): "I am not interested in smoking cessation."; stage 2 (the precontemplation stage): "I am interested in smoking cessation, but have no plan within the next 6 months."; stage 3 (the contemplation stage): "I'd like to quit smoking within the next 6 months, but I have no plan within 1 month."; and stage 4 (the preparation stage): "I'd like to quit smoking within 1 month." [23] These categories are based on the transtheoretical model and stages of change theory [24, 25], which posits that individuals progress through these four stages of change on their way toward adopting a healthy behavior or toward cessation of an unhealthy behavior before making and sustaining the behavior change. Thus, smokers in the four stages differ from each other, and would have different outcomes related to quitting tobacco in the future [26].

\section{Methods of smoking cessation}

Participants were also asked to answer a question to confirm cessation-aids use [27], as follows: "Did you quit smoking for 24 hours or more aiming to quit smoking in the past year?" When they responded "yes" to this question, they were also asked to answer the next question about the methods of smoking cessation and to select from the following options: 1) smoking cessation treatment at a hospital, or 2) other methods including self-directed methods.

\section{The heavy smoking index}

The Heavy Smoking Index (HSI) is composed of two items derived from the Fagerström Test for Nicotine Dependence $[28,29]$. Participants were asked to answer two questions about the mean number of cigarettes smoked per day and the time from waking to smoking the first cigarette. This test is used to estimate the degree of nicotine dependence among daily smokers [30], and consists of two items with an overall score of 0-6 with higher HSI scores indicating greater nicotine dependence.

\section{Outcomes}

The primary outcomes of this study were as follows: 1) the percentage of participants at each smoking cessation stage, and 2) change in smoking cessation stage after 1 year among current smokers in the cohort. Secondary outcomes were as follows: 3) smoking cessation rate, and 4) methods of smoking cessation. These outcomes were reported by sex.

\section{Results}

Fig. 1 shows the study recruitment process. Data were analyzed for 350 participants (83.3\%) of the 420 patients randomly extracted from the 680-patient pool, and 70 were eligible but not recruited during the survey period because of their medical condition or decline. Of the 350 participants, 113 (32.2\%) were current smokers, 68 (19.4\%) were current nonsmokers (former smokers), and 169 (48.3\%) had never smoked. Thus, the follow up study was scheduled for the 113 current smokers, and 104 participants (tracking rate, 92\%) were successfully tracked after 1 year.

Tables 1 and 2 show participants' characteristics and the current smokers' HSI scores by sex. The number of current nonsmokers who had already quit smoking at baseline included 38 (21.8\%) men and 30 (17.0\%) 
Samples in the Study of Health Behavior in People with Schizophrenia (SHEAPS)

No. of patients who visited the outpatient clinic $\geq$ two times in the last 6 months; visited for at least 1 year as of April 1, 2016; diagnosed with schizophrenia or schizoaffective disorders; and aged 20-69 years $n=907$ (male: 447, female:460)

\begin{tabular}{|c|c|c|}
\hline & $\begin{array}{l}\text { Excluded } \\
\text { Comorbid for intellectual disabilities } \\
\text { Psychiatric symptoms too severe to participate in the study } \\
\text { Inability to read or write } \\
\text { Physical status too severe to participate in the study }\end{array}$ & $\begin{array}{l}n=227(\mathrm{~m}: 115, \mathrm{f}: 112) \\
n=73(\mathrm{~m}: 38, \mathrm{f}: 35) \\
n=145(\mathrm{~m}: 73, \mathrm{f}: 72) \\
n=7(\mathrm{~m}: 4, \mathrm{f}: 3) \\
n=2(\mathrm{f}: 2)\end{array}$ \\
\hline Eligible patients for the SHEAPS & $n=680(\mathrm{~m}: 332, \mathrm{f}: 348)$ & \\
\hline \multirow[t]{2}{*}{ Randomly-selected } & $n=420(\mathrm{~m}: 206, \mathrm{f}: 214)$ & \\
\hline & $\begin{array}{l}\text { Eligible but not recruited during the questionnaire survey period } \\
\text { Psychiatric symptoms too severe to participate in the study } \\
\text { Physical status too severe to participate in the study } \\
\text { Death } \\
\text { Declined to participate }\end{array}$ & $\begin{aligned} n & =13(\mathrm{~m}: 6, \mathrm{f}: 7) \\
n & =1(\mathrm{f}: 1) \\
n & =2(\mathrm{~m}: 2) \\
n & =54(\mathrm{~m}: 24, \mathrm{f}: 30)\end{aligned}$ \\
\hline \multirow[t]{2}{*}{$\begin{array}{l}\text { Questionnaire administered } \\
\text { Currently smoker (target of longitudinal exam } \\
\text { Currently nonsmoker } \\
\text { Never smoke }\end{array}$} & ination) $\quad \begin{aligned} n= & 350(\mathrm{~m}: 174, \mathrm{f}: 176) \\
& n=113(\mathrm{~m}: 79, \mathrm{f}: 34) \\
& n=68(\mathrm{~m}: 38, \mathrm{f}: 30) \\
& n=169(\mathrm{~m}: 57, \mathrm{f}: 112)\end{aligned}$ & \\
\hline & $\begin{array}{l}\text { Eligible but not recruited during the questionnaire survey perioc } \\
\text { Death } \\
\text { Psychiatric symptoms too severe to participate in the study } \\
\text { Unable to contact }\end{array}$ & $\begin{array}{l}n=4(\mathrm{~m}: 4) \\
n=2(\mathrm{~m}: 1, \mathrm{f}: 1) \\
n=3(\mathrm{~m}: 2, \mathrm{f}: 1)\end{array}$ \\
\hline Follow-up questionnaire administered & $n=104(\mathrm{~m}: 72, \mathrm{f}: 32)$ & \\
\hline
\end{tabular}

Fig. 1 Flow diagram of the participant recruitment process. $m$, male; f, female

women, and among these, $4(10.5 \%)$ men and $3(10.0 \%)$ women had received smoking cessation treatment. Among the 79 male and 34 female participants who were still smoking at baseline, 39 (49.3\%) men and 17 (50.0\%) women had failed in their smoking cessation attempts in the year before baseline, and $6(15.4 \%)$ of the men and $1(5.8 \%)$ woman had received smoking cessation treatment.

Table 3 shows the numbers of participants at each smoking cessation stage for current smokers at baseline and at follow-up for outcome 1), and the number of those who quit smoking during the surveys for outcome 3). Smokers at smoking cessation stage $\geq 2$ (interested in smoking cessation) included $51(64.6 \%)$ men and $28(82.3 \%)$ women at baseline. At the end of the follow-up survey in 2017, the numbers of smokers at stage $\geq 2$ included 46 (69.9\%) men and $24(81.2 \%)$ women, and only $4(5.6 \%)$ men and 2 (6.3\%) women successfully quit smoking.

Fig. 2 shows how the smoking cessation stage changed between surveys by sex for outcome 2 and the details of participants who successfully stopped smoking between surveys for outcome 4 . The highest number of participants were at stage 2 at both baseline and follow-up. According to the transtheoretical theory, after a 1-year follow-up, all participants at stage $\geq 3$ should have stopped smoking. However, only 6 participants quit smoking, and 16 participants were at an earlier stage compared with baseline. In men, among six smokers at stage 4 at baseline, two quit smoking on their own. No women quit smoking among the three women at stage 4; however, among five women at stage 3 at baseline, one quit smoking on her own. Among the six men and women who quit smoking, only one received smoking cessation treatment, and the remaining five quit on their own. Participants at stage $\geq 2$ at both baseline and follow-up included 36 (50.0\%) men, and 22 (68.8\%) women.

\section{Discussion}

As reference data, the smoking rate we independently calculated from data from the Okayama City Comprehensive Survey of Living Conditions 2013 provided by 
Table 1 Male participants' characteristics $(n=174)$

\begin{tabular}{|c|c|c|c|}
\hline & Current smoker & Current nonsmoker & Never smoker \\
\hline$n(\%)$ & $79(45.4 \%)$ & $38(21.8 \%)$ & $57(32.7 \%)$ \\
\hline Age $(y)$ mean \pm SD [min-max] & $45.6 \pm 11.1[22-69]$ & $49.8 \pm 11.3[27-66]$ & $39.9 \pm 11.2[20-67]$ \\
\hline $\mathrm{CP}$ mean $\pm \mathrm{SD}[\text { min-max }]^{\mathrm{a}}$ & $693 \pm 431[38-2011]$ & $545 \pm 359[25-1645]$ & $680 \pm 490[0-2556]$ \\
\hline $\mathrm{mGAF}$ score mean $\pm \mathrm{SD}[\text { min-max }]^{\mathrm{b}}$ & $53 \pm 15[21-88]$ & $51 \pm 13[25-82]$ & $51 \pm 13[21-81]$ \\
\hline \multicolumn{4}{|l|}{ Marital status } \\
\hline married & 9 & 14 & 3 \\
\hline unmarried & 58 & 23 & 50 \\
\hline separated & 1 & 0 & 1 \\
\hline divorced & 11 & 1 & 3 \\
\hline widowed & 0 & 0 & 0 \\
\hline \multicolumn{4}{|l|}{ Educational level } \\
\hline$\leq$ junior high school & 15 & 6 & 9 \\
\hline \multicolumn{4}{|c|}{$>$ junior high school but $\leq$ high school } \\
\hline & 38 & 12 & 26 \\
\hline \multicolumn{4}{|c|}{$>$ high school but $\leq$ junior/vocational college } \\
\hline & 12 & 8 & 7 \\
\hline$\geq$ university or college & 14 & 12 & 15 \\
\hline \multicolumn{4}{|l|}{ Heavy Smoking Index score } \\
\hline 0 & 4 & - & - \\
\hline 1 & 4 & - & - \\
\hline 2 & 8 & - & - \\
\hline 3 & 20 & - & - \\
\hline 4 & 22 & - & - \\
\hline 5 & 12 & - & - \\
\hline 6 & 9 & - & - \\
\hline \multicolumn{4}{|l|}{ Smoking cessation trial } \\
\hline failed & 39 & - & - \\
\hline no & 40 & - & - \\
\hline \multicolumn{4}{|l|}{ Method of smoking cessation } \\
\hline treatment & 6 & 4 & - \\
\hline self-directed & 33 & 34 & - \\
\hline
\end{tabular}

${ }^{a}$ Equivalent dose of chlorpromazine (CP)

${ }^{\mathrm{b}}$ The modified Global Assessment of Functioning scale (mGAF)

SD standard deviation

the Ministry of Health, Labour and Welfare in Japan was $35.4 \%$ for men and $10.0 \%$ for women [31]. We used these data because approximately $60 \%$ of our participants lived in the same area, and the most recent available data on smoking rates for external reference were reported in the 2013 Ministry of Health, Labour and Welfare national survey. The smoking rate in the present study was $45.4 \%$ for men and $19.3 \%$ for women. This result is similar to the latest meta-analysis from Japan reporting smoking rates among patients with schizophrenia (men: 52.9\%, women 24.4\%) [5]. Thus, the smoking rate in patients with schizophrenia in the present study was higher than the reference for the general population for approximately the same time and area, as we hypothesized. Our results showed that more than half of the patients with schizophrenia in our study who had smoked were interested in smoking cessation, but results also showed that $<10 \%$ of smokers were able to achieve smoking cessation in 1 year. By tracking the stage changes in this study, we saw that some participants who had intentions to quit smoking within at least 6 months from baseline, retreated from the 
Table 2 Female participants' characteristics $(n=176)$

\begin{tabular}{|c|c|c|c|}
\hline & Current smoker & Current nonsmoker & Never smoker \\
\hline n (\%) & $34(19.3 \%)$ & $30(17.0 \%)$ & $112(63.6 \%)$ \\
\hline Age $(y)$ mean $\pm S D[$ min-max $]$ & $41.3 \pm 10.8[22-60]$ & $46.4 \pm 10.4[24-63]$ & $46.0 \pm 13.3[21-69]$ \\
\hline $\mathrm{CP}$ mean $\pm \mathrm{SD}[\text { min-max }]^{\mathrm{a}}$ & $694 \pm 464[75-1886]$ & $501 \pm 287[71-1212]$ & $509 \pm 380[0-1767]$ \\
\hline mGAF mean \pm SD score $[\text { min-max }]^{b}$ & $53 \pm 15[24-88]$ & $51 \pm 14[25-85]$ & $\begin{array}{l}56 \pm 15[20-86] \\
(n=5: \text { missing })\end{array}$ \\
\hline \multicolumn{4}{|l|}{ Marital status } \\
\hline married & 8 & 9 & 39 \\
\hline unmarried & 20 & 8 & 55 \\
\hline separated & 0 & 2 & 1 \\
\hline divorced & 6 & 9 & 12 \\
\hline widowed & 0 & 2 & 5 \\
\hline \multicolumn{4}{|l|}{ Educational level } \\
\hline$\leq$ junior high school & 5 & 1 & 11 \\
\hline \multicolumn{4}{|c|}{$>$ junior high school but $\leq$ high school } \\
\hline & 15 & 14 & 50 \\
\hline \multicolumn{4}{|c|}{$>$ high school but $\leq$ junior/vocational college } \\
\hline & 9 & 13 & 34 \\
\hline$\geq$ university or college & 5 & 2 & 17 \\
\hline \multicolumn{4}{|l|}{ Heavy Smoking Index score } \\
\hline 0 & 2 & - & - \\
\hline 1 & 2 & - & - \\
\hline 2 & 4 & - & - \\
\hline 3 & 6 & - & - \\
\hline 4 & 13 & - & - \\
\hline 5 & 3 & - & - \\
\hline 6 & 4 & - & - \\
\hline \multicolumn{4}{|l|}{ Smoking cessation trial } \\
\hline failed & 17 & - & - \\
\hline no & 17 & - & - \\
\hline \multicolumn{4}{|l|}{ Method of smoking cessation } \\
\hline treatment & 1 & 3 & - \\
\hline self-directed & 16 & 27 & - \\
\hline
\end{tabular}

${ }^{a}$ Equivalent dose of chlorpromazine (CP)

${ }^{\mathrm{b}}$ The modified Global Assessment of Functioning scale (mGAF)

SD standard deviation

contemplation/preparation stage to the immotive/precontemplation stage (not interested in/interested in but not within 6 months). Many participants stayed at the precontemplation stage and did not advance.

A previous long-term follow up study reported smoking reduction among smokers with schizophrenia from the results of smoking status change [32]. In the current survey about smoking cessation stage, many participants dropped in stage, which confirms that it is difficult to achieve smoking cessation. A previous study reported that patients with schizophrenia do want to quit, but typically do not quit in the absence of evidence-based smoking cessation treatment, such as pharmacotherapy with behavioral counseling [33]. Complex active strategies that include evidence-based interventions and environmental adjustment, such as smoke-free hospital settings both indoors and outdoors and prohibition of staff smoking, should be implemented regardless of the individual's smoking cessation stage. However, it should be noted that individuals' attitudes, strategies, and skills differ at varying stages of 
Table 3 Smoking cessation stage of current smokers in 2016 and 2017 by sex

\begin{tabular}{|c|c|c|c|c|c|}
\hline & & \multicolumn{2}{|c|}{ Current smoker in 2016} & \multicolumn{2}{|c|}{ Current smoker in 2017} \\
\hline & & $\begin{array}{l}\text { men } \\
n=79 \text { (100\%) }\end{array}$ & $\begin{array}{l}\text { women } \\
n=34(100 \%)\end{array}$ & $\begin{array}{l}\text { men } \\
n=72(100 \%)\end{array}$ & $\begin{array}{l}\text { women } \\
n=32(100 \%)\end{array}$ \\
\hline \multirow[t]{4}{*}{ Smoking cessation stage } & stage 1 & $28(35.4 \%)$ & $6(17.7 \%)$ & $22(30.1 \%)$ & $6(18.8 \%)$ \\
\hline & stage 2 & $33(41.8 \%)$ & $18(53.0 \%)$ & $40(55.6 \%)$ & $18(56.2 \%)$ \\
\hline & stage 3 & $9(11.4 \%)$ & $6(17.7 \%)$ & $3(4.2 \%)$ & $3(9.4 \%)$ \\
\hline & stage 4 & $9(11.4 \%)$ & $4(11.8 \%)$ & $3(4.2 \%)$ & $3(9.4 \%)$ \\
\hline Stopped smoking & & - & - & $4(5.6 \%)$ & $2(6.3 \%)$ \\
\hline
\end{tabular}

the health-behavior change process [34], and these stages reflect the readiness of behavior change. Although there is limited evidence to support the efficacy of stage-based interventions in changing smoking behavior [35], we might need to intervene for patients with schizophrenia who want to quit smoking, as the present study shows. However, the type of instructive intervention needed at each smoking stage to help patients progress in the smoking cessation stages has not yet been established.

In the Japanese general population, the annual rate of smoking cessation attempts is $28.3 \%$, and the annual rate of specialized smoking cessation treatment at hospitals is $7.4 \%$ [36]. We found that the selection ratio of smoking cessation treatment among those who tried to quit smoking in this study was comparable, though many failed, and at baseline, most women did not choose smoking cessation aids such as treatment at hospitals.
There may be insufficient opportunities for smoking cessation treatment and education, especially for women with schizophrenia. Smoking cessation drugs are reportedly effective and safe in assisting smoking cessation in patients with schizophrenia [37], and these medications might be easily obtained to begin immediate treatment [38]. One meta-analysis showed that the cessation rates after treatment of smoking cessation drugs were significantly higher than placebo treatment (risk ratio: 3.034.74) [39]. Valenicline has been reported to be more effective than nicotine patches in women [40]. However, a web-based survey in Japan reported that over $70 \%$ of smokers did not use any therapy or assistance [41], and national data have shown that many psychiatric institutions do not offer smoking cessation treatment by public health insurance in Japan [42]. Therefore, the importance of drug treatment needs to be recognized.

\begin{tabular}{|c|c|c|c|c|c|c|c|}
\cline { 3 - 8 } \multicolumn{2}{c|}{} & \multicolumn{6}{c|}{ Smoking cessation stage in 2017 (men) } \\
\cline { 2 - 9 } \multicolumn{2}{c|}{} & 1 & 2 & 3 & 4 & $\begin{array}{c}\text { Stopped } \\
\text { smoking }\end{array}$ & Total \\
\hline \multirow{3}{*}{$\begin{array}{c}\text { Smoking } \\
\text { cessation } \\
\text { stage in 2016 } \\
\text { (men) }\end{array}$} & 1 & 13 & 9 & 1 & 0 & $1(\mathrm{a})$ & 24 \\
\cline { 2 - 9 } & 2 & 7 & 22 & 1 & 1 & $1(\mathrm{~b})$ & 32 \\
\cline { 2 - 9 } & 4 & 1 & 6 & 1 & 0 & 0 & 8 \\
\cline { 2 - 9 } & Total & 22 & 40 & 3 & 3 & 4 & 72 \\
\hline
\end{tabular}

\begin{tabular}{|c|c|c|c|c|c|c|c|}
\cline { 3 - 8 } \multicolumn{2}{c|}{} & \multicolumn{6}{|c|}{ Smoking cessation stage in 2017 (women) } \\
\cline { 2 - 9 } \multicolumn{2}{c|}{} & 1 & 2 & 3 & 4 & $\begin{array}{c}\text { Stopped } \\
\text { smoking }\end{array}$ & Total \\
\hline \multirow{3}{*}{$\begin{array}{c}\text { Smoking } \\
\text { cessation } \\
\text { stage in 2016 } \\
\text { (women) }\end{array}$} & 1 & 3 & 2 & 0 & 0 & $1(\mathrm{e})$ & 6 \\
\cline { 2 - 9 } & 2 & 3 & 11 & 1 & 2 & 0 & 17 \\
\cline { 2 - 9 } & 4 & 0 & 3 & 2 & 0 & $1(\mathrm{f})$ & 6 \\
\cline { 2 - 9 } & Total & 6 & 18 & 3 & 3 & 2 & 32 \\
\hline
\end{tabular}

Fig. 2 Changes in smoking cessation stage from 2016 to 2017 by sex and age, method of smoking cessation, and HSI. (a) (male) 67 y, selfdirected, $\mathrm{HSI}=2$; (b) (male) $43 \mathrm{y}$, self-directed, $\mathrm{HSI}=3$; (c) (male) $63 \mathrm{y}$, self-directed, HSI =0; (d) (male) $42 \mathrm{y}$, self-directed, HSI =0; (e) (female) $46 \mathrm{y}$, hospital-directed treatment, $\mathrm{HSI}=1$; (f) $58 \mathrm{y}$, self-directed, $\mathrm{HSI}=4$. HSI, Heavy Smoking Index. Stage 1 (the immotive stage): "I am not interested in smoking cessation.". Stage 2 (the precontemplation stage): "I am interested in smoking cessation, but have no plan within the next 6 months.". Stage 3 (the contemplation stage): "I'd like to quit smoking within the next 6 months, but I have no plan to within 1 month.". Stage 4 (the preparation stage): "I'd like to quit smoking within 1 month" 
This study has several limitations that should be considered. First, the self-reported data could have resulted in misclassification of data. However, self-reported smoking status is reported to be positively-related to the carbon monoxide level in expired air, and this is a reliable method for evaluating the smoking status of patients with schizophrenia regardless of their sex [43, 44]. Second, participants were recruited from a single outpatient clinic in a psychiatric hospital. Thus, the generalizability of data from this population has a clear limit. For this reason, we did not analyze the associations between patients' background characteristics and smoking behavior, and focused mainly on changes in smoking preference. Second, our sample included many severely-affected patients, and generalization of the results is limited because of selection bias. Patients with more severe symptoms might have been more likely to decline to participate in this survey or to answer the questionnaire, which could have led to an underestimation of the number of current smokers. Third, the applicability of our findings to other countries with different health care systems regarding smoking cessation is unknown. Fourth, we only surveyed the intention to quit smoking, and did not investigate how much the number of cigarettes per day changed. Therefore, we cannot make any conclusions about the relationship between stage change and behavior change. Fifth, to date, there is little research on changes in smoking cessation levels in the general Japanese population that can be compared with this report. Therefore, future reports about this issue are needed.

\section{Conclusion}

This study showed that few patients were offered aids and few patients quit smoking, although many smokers with schizophrenia were interested in smoking cessation. Without smoking cessation aids, intentions for smoking cessation may not proceed or may decrease. Considering that only $10 \%$ of our participants received smoking cessation treatment (even though many intended to quit smoking), interventions for cessation treatment are necessary, especially for those at the contemplation/preparation stage. It is necessary to develop effective smoking cessation interventions for smoking patients with schizophrenia.

\section{Abbreviations}

HSI: Heavy smoking index; SHEAPS: Study of health behavior in people with schizophrenia

\section{Acknowledgments}

We thank Ms. Kimiko Takaoka, who was a research assistant and helped administer the questionnaire survey, Ms. Megumi Miki who assisted with data management, Ms. Shoko Yoshimoto who supported our study with logistics assistance, and all the outpatient service staff at the Okayama Psychiatric Medical Center. We also thank Jane Charbonneau, DVM, and Nia Cason, PhD, from Edanz Group (www.edanzediting.com/ac) for editing a draft of this manuscript.

\section{Authors' contributions}

YH contributed to the study design, conducted all analyses, and drafted the manuscript. MF1 and MI wrote the study protocol and performed the questionnaire survey. NN, MF2, CH, KK, YU, and NY contributed to the study design and interpreted the results. RS, IS, KS, YY, MK, HT, and YK contributed to the study design and data acquisition. All authors revised the manuscript and approved the final version.

\section{Funding}

This study was supported by the Okayama Health Foundation, Novartis Pharma Research Grants, Research for Promotion of Cancer Control Programs (H26political-general-002), and grants from Eisai. These sources had no further role in study design; in the collection, analysis or interpretation of data; in the writing of the report; or in the decision to submit the paper for publication.

\section{Availability of data and materials}

The datasets generated and/or analyzed during the current study are not publicly available due the terms of consent to which the participants agreed, but may be available from the corresponding author on reasonable request.

\section{Ethics approval and consent to participate}

Ethical approval was given by the institutional ethics committee of the Okayama University Graduate School of Medicine, Dentistry, and Pharmaceutical Sciences and the institutional review board of Okayama University Hospital (approval number KEN1608-010), and by the Okayama Psychiatric Medical Center (approval number 27-38). All participants provided written informed consent.

\section{Consent for publication}

Not applicable.

\section{Competing interests}

$\mathrm{YH}$ has nothing to disclose related to this paper. MF1 reports grants from: Okayama Health Foundation, Novartis Pharma, Research for Promotion of Cancer Control Programs, and Eisai Co., Ltd. during this study; and personal fees from: Mochida Pharmaceutical Co., Ltd., Eli Lilly Japan K.K., Sumitomo Dainippon Pharma Co., Ltd., Sentan Igaku-sha Ltd., Igaku-Shoin Ltd., Iyaku (Medicine and Drug) Journal Co., Ltd. outside the submitted work. RS reports personal fees from Kagakuhyronsha Co., Ltd., Medical Review Co., Ltd., Otsuka Pharmaceutical Co., Ltd., Igaku Shoin Co., Ltd. outside the submitted work. KK reports personal fees from Mochida Pharmaceutical Co., Ltd. outside the submitted work. NY reports grants from Okayama Health Foundation, Novartis Pharma, Research for Promotion of Cancer Control Programs, and Eisai Co., Ltd. during this study; grants from the Japanese Ministry of Education, Science, and Technology; grants and personal fees from Daiichi Sankyo Co., Ltd., Eisai Co., Ltd., and Otsuka Pharmaceutical Co., Ltd.; grants from Astellas Pharma Inc., and grants and personal fees from MSD KK and Pfizer Inc.; personal fees from Meiji Seika Pharma Co., Ltd., Janssen Pharmaceutical KK, Hisamitsu Pharmaceutical Co., Inc., Sumitomo Dainippon Pharma Co., Ltd., Mochida Pharmaceutical Co., Ltd., and Tsumura \& Co.; and grants and personal fees from Takeda Pharmaceutical Co., Ltd. outside the submitted work. Ml reports grants from Okayama Health Foundation, Novartis Pharma, Research for Promotion of Cancer Control Programs during this study; grants and personal fees from Takeda Pharmaceutical Co., Ltd., Pfizer Inc., Eisai Co., Ltd., and MSD KK; grants from Astellas Pharma Inc. and Daiichi Sankyo Co., Ltd.; personal fees from Meiji Seika Pharma Co., Ltd., Mochida Pharmaceutical Co., Ltd., Novartis Pharma, Otsuka Pharmaceutical Co., Ltd., Yoshitomiyakuhin Corporation, and Technomics, Inc., outside the submitted work. The other authors have nothing to disclose related to this paper.

\section{Author details}

'Taiyo Hills Hospital, 2200 Abe, Ochiaicho, Takahashi City, Okayama 716-0061, Japan. ${ }^{2}$ Department of Neuropsychiatry, Okayama University Hospital, 2-5-1 Shikata-cho, Kita-ku, Okayama 700-8558, Japan. ${ }^{3}$ Department of Preventive Medicine and Epidemiology, Tohoku Medical Megabank Organization, Tohoku University, 2-1 Seiryo, Sendai 980-8573, Japan. ${ }^{4}$ Division of Health Care Research, Behavioral Sciences and Survivorship Research and Division of Cohort Consortium Research, Epidemiology and Prevention Group, Center for Public Health Sciences, National Cancer Center, Tsukiji, Chuo-ku, Tokyo 104-0045, Japan. ${ }^{5}$ Division of Occupational Therapy, Faculty of Care and Rehabilitation, Seijoh University, 2-172 Fukinodai, Tokai City, Aichi 476-8588, Japan. ${ }^{6}$ Okayama Psychiatric Medical Center, 3-16 Shikatahon-machi, Kita-ku, Okayama 700-0915, Japan. ${ }^{7}$ Department of Neuropsychiatry, Kochi Medical School, Kochi University, Kohasu, Oko-cho, Nankoku, Kochi 783-8505, Japan. ${ }^{8}$ Innovation Center for Supportive, Palliative and Psychosocial Care, National Cancer Center Hospital and Behavioral Sciences and Survivorship Research, 
Center for Public Health Sciences, National Cancer Center, Tsukiji, Chuo-ku, Tokyo 104-0045, Japan. ${ }^{9}$ Department of Neuropsychiatry, Okayama University Graduate School of Medicine, Dentistry, and Pharmaceutical Science, 2-5-1 Shikata-cho, Kita-ku, Okayama 700-8558, Japan. ${ }^{10}$ Department of Psychiatry, Faculty of Medicine, Shimane University, 89-1 Enya-cho, Izumo, Shimane 693-8501, Japan.

Received: 13 March 2019 Accepted: 31 October 2019

\section{Published online: 21 November 2019}

\section{References}

1. de Leon J, Becona E, Gurpegui M, Gonzalez-Pinto A, Diaz FJ. The association between high nicotine dependence and severe mental illness may be consistent across countries. J Clin Psychiatry. 2002;63(9):812-6.

2. Wang $Y Y$, Wang $S$, Zheng W, Zhong BL, Ng CH, Ungvari GS, Wang $C X$, Xiang YT, Li XH. Cognitive functions in smoking and non-smoking patients with schizophrenia: a systematic review and meta-analysis of comparative studies. Psychiatry Res. 2019;272:155-63.

3. Sagud M, Mihaljevic Peles A, Pivac N. Smoking in schizophrenia: recent findings about an old problem. Curr Opin Psychiatry. 2019;32(5):402-8.

4. de Leon J, Diaz FJ. A meta-analysis of worldwide studies demonstrates an association between schizophrenia and tobacco smoking behaviors. Schizophr Res. 2005;76(2-3):135-57.

5. Ohi K, Shimada T, Kuwata A, Kataoka Y, Okubo H, Kimura K, Yasuyama T, Uehara T, Kawasaki Y. Smoking rates and number of cigarettes smoked per day in schizophrenia: a large cohort meta-analysis in a Japanese population. Int J Neuropsychopharmacol. 2019;22(1):19-27.

6. Crump C, Winkleby MA, Sundquist K, Sundquist J. Comorbidities and mortality in persons with schizophrenia: a Swedish national cohort study. Am J Psychiatry. 2013;170(3):324-33.

7. Sankaranarayanan A, Mancuso S, Wilding H, Ghuloum S, Castle D. Smoking, Suicidality and psychosis: a systematic meta-analysis. PLoS One. 2015;10(9): e0138147.

8. Sharma R, Gartner CE, Hall WD. The challenge of reducing smoking in people with serious mental illness. Lancet Respir Med. 2016;4(10):835-44.

9. Cook BL, Wayne GF, Kafali EN, Liu Z, Shu C, Flores M. Trends in smoking among adults with mental illness and association between mental health treatment and smoking cessation. JAMA. 2014;311(2):172-82.

10. GBD 2015 Tobacco Collaborators. Smoking prevalence and attributable disease burden in 195 countries and territories, 1990-2015: a systematic analysis from the Global Burden of Disease Study 2015. Lancet. 2017; 389(10082):1885-906.

11. Prochaska JJ, Das S, Young-Wolff KC. Smoking, mental illness, and public health. Annu Rev Public Health. 2017;38:165-85.

12. Tidey JW, Miller ME. Smoking cessation and reduction in people with chronic mental illness. BMJ. 2015;351:h4065.

13. Prochaska JJ. Smoking and mental illness--breaking the link. N Engl J Med. 2011;365(3):196-8.

14. Schroeder SA. Smoking cessation should be an integral part of serious mental illness treatment. World Psychiatry. 2016;15(2):175-6.

15. Poland B, Frohlich K, Haines RJ, Mykhalovskiy E, Rock M, Sparks R. The social context of smoking: the next frontier in tobacco control? Tob Control. 2006; 15(1):59-63.

16. American Cancer Society. The Tobacco Atlas. 2019. https://tobaccoatlas.org/. Accessed 30 Jan 2019.

17. Fujiwara M, Inagaki M, Nakaya N, Fujimori M, Higuchi Y, Kakeda K, Uchitomi Y, Yamada N. Smoking among adults with serious psychological distress: analysis of anonymized data from a national cross-sectional survey in Japan. J Affect Disord. 2018;239:131-7.

18. Kure $\mathrm{S}$, Kashida $\mathrm{G}$. The state of private confinement and its statistical observation of the mentally ill: modern translation. (in Japanese). Tokyo: Igakushoin; 2012.

19. Hashimoto K, Makinodan M, Matsuda Y, Morimoto T, Ueda S, Kishimoto T. Smoking bans in mental health hospitals in Japan: barriers to implementation. Ann General Psychiatry. 2015;14:35.

20. Fujiwara M, Inagaki M, Nakaya N, Fujimori M, Higuchi Y, Hayashibara C, So R, Kakeda K, Kodama M, Uchitomi Y, et al. Cancer screening participation in schizophrenic outpatients and the influence of their functional disability on the screening rate: a cross-sectional study in Japan. Psychiatry Clin Neurosci. 2017;71(12):813-25.
21. American Psychiatric Association. Diagnostic and statistical manual of mental disorders, 5th edition. Washington, DC: American Psychiatric Association; 2013.

22. World Health Organization. Guidelines for Controlling and Monitoring the Tobacco Epidemic: World Health Organization; 1998.

23. Nakamura M, Masui S, Oshima A, Okayama A, Ueshima H, Group HR. Effects of stage-matched repeated individual counseling on smoking cessation: a randomized controlled trial for the high-risk strategy by lifestyle modification (HISLIM) study. Environ Health Prevent Med. 2004;9(4):152-60.

24. Prochaska JO, DiClemente CC. Stages and processes of self-change of smoking: toward an integrative model of change. J Consult Clin Psychol. 1983;51(3):390-5.

25. Prochaska JO, Velicer WF. Misinterpretations and misapplications of the transtheoretical model. Am J Health Promot. 1997;12(1):11-2.

26. Dijkstra A, Roijackers J, De Vries H. Smokers in four stages of readiness to change. Addict Behav. 1998;23(3):339-50.

27. Cokkinides VE, Ward E, Jemal A, Thun MJ. Under-use of smoking-cessation treatments: results from the National Health Interview Survey, 2000. Am J Prev Med. 2005;28(1):119-22.

28. Heatherton TF, Kozlowski LT, Frecker RC, Rickert W, Robinson J. Measuring the heaviness of smoking: using self-reported time to the first cigarette of the day and number of cigarettes smoked per day. Br J Addict. 1989;84(7):791-9.

29. Etter JF, Duc TV, Perneger TV. Validity of the Fagerstrom test for nicotine dependence and of the heaviness of smoking index among relatively light smokers. Addiction. 1999;94(2):269-81.

30. Perez-Rios M, Santiago-Perez Ml, Alonso B, Malvar A, Hervada X, de Leon J. Fagerstrom test for nicotine dependence vs heavy smoking index in a general population survey. BMC Public Health. 2009;9:493.

31. Statistics Bureau Ministry of Internal Affairs and Communications. Portal site of official statistics of Japan. 2017. Available from: https://www.e-stat.go.jp/ en. Accessed 30 Jan 2019.

32. Baker A, Richmond R, Lewin TJ, Kay-Lambkin F. Cigarette smoking and psychosis: naturalistic follow up 4 years after an intervention trial. Aust N Z J Psychiatry. 2010;44(4):342-50.

33. Cather C, Pachas GN, Cieslak KM, Evins AE. Achieving smoking cessation in individuals with schizophrenia: special considerations. CNS Drugs. 2017;31(6):471-81.

34. Noar SM, Benac CN, Harris MS. Does tailoring matter? Meta-analytic review of tailored print health behavior change interventions. Psychol Bull. 2007; 133(4):673-93.

35. Riemsma RP, Pattenden J, Bridle C, Sowden AJ, Mather L, Watt IS, Walker A. Systematic review of the effectiveness of stage based interventions to promote smoking cessation. BMJ. 2003;326(7400):1175-7.

36. Nakamura M. Article 14 of the World Health Organization framework convention on tobacco control: demanding reduction measures concerning tobacco dependence and cessation. (in Japanese). Hoken Iryo Kagaku. 2015;64(5):475-83.

37. Ahmed S, Virani S, Kotapati VP, Bachu R, Adnan M, Khan AM, Zubair A, Begum G, Kumar J, Qureshi M, et al. Efficacy and safety of Varenicline for smoking cessation in schizophrenia: a meta-analysis. Front Psychiatry. 2018;9:428.

38. Leischow SJ. Increasing smoking cessation in the United States: expanding the availability of over-the-counter medications. JAMA. 2019;321(6):541-2.

39. Tsoi DT, Porwal M, Webster AC. Interventions for smoking cessation and reduction in individuals with schizophrenia. Cochrane Database Syst Rev. 2013;2:CD007253.

40. Smith PH, Zhang J, Weinberger AH, Mazure CM, McKee SA. Gender differences in the real-world effectiveness of smoking cessation medications: findings from the 2010-2011 tobacco use supplement to the current population survey. Drug Alcohol Depend. 2017;178:485-91.

41. Igarashi A, Negishi S, Goto R, Suwa K. Web-based survey on smoking cessation behaviors of current and former smokers in Japan. Curr Med Res Opin. 2014;30(10):1911-21.

42. Central Social Insurance Medical Council. Research report on the effects of smoking cessation treatment covered by health insurance (in Japanese). 2017. https://www.mhlw.go.jp/file/05-Shingikai-12404000-HokenkyokuIryouka/0000192293.pdf. Accessed 9 Aug 2019.

43. Takeuchi T, Nakao M, Shinozaki Y, Yano E. Validity of self-reported smoking in schizophrenia patients. Psychiatry Clin Neurosci. 2010;64(3):274-8.

44. Takeuchi T, Nakao M, Shinozaki Y, Yano E. Validity of the self-reported smoking status of schizophrenia patients, taking gender-related differences into consideration. Int J Psychiatry Clin Pract. 2010;14(4):282-6.

\section{Publisher's Note}

Springer Nature remains neutral with regard to jurisdictional claims in published maps and institutional affiliations. 